\title{
Cardiac magnetic resonance
} for asymptomatic patients with type 2 diabetes and cardiovascular high risk (CATCH): a pilot study

Ming-Yen $\mathrm{Ng}^{1,2^{*}}$, Wenli Zhou ${ }^{1}$, Varut Vardhanabhuti ${ }^{1}$, Chi-Ho Lee ${ }^{3}$, Esther Yee Tak Yu ${ }^{4}$, Eric Yuk Fai Wann ${ }^{4}$ Kit Chan ${ }^{5}$, Andrew T. Yan ${ }^{6,7}$, Tai-Pang Ip ${ }^{8}$, Kai-Hang Yiu ${ }^{3,5}$ and Bernd J. Wintersperger 9,10

\begin{abstract}
Background: Stress cardiovascular magnetic resonance (CMR) to screen for silent myocardial ischaemia in asymptomatic high risk patients with type 2 diabetes mellitus (DM) has never been performed, and its effectiveness is unknown. Our aim was to determine the feasibility of a screening programme using stress CMR by obtaining preliminary data on the prevalence of silent ischaemia caused by obstructive coronary artery disease (CAD) and quantify myocardial perfusion in asymptomatic high risk patients with type 2 diabetes.
\end{abstract}

Methods: In this prospective cohort study, we recruited 63 asymptomatic DM patients (mean age 66 years \pm 4.4 years; $77.8 \%$ male); with Framingham risk score $\geq 20 \%$ from 3 sites from June 2017 to August 2018. Normal volunteers were recruited to determine normal global myocardial perfusion reserve index (MPRI). Adenosine stress CMR and global MPRI was performed and measured in all subjects. Positive stress CMR cases were referred for catheter coronary angiography (CCA) with/without fractional flow reserve (FFR) measurements. Positive CCA was defined as an FFR $\leq 0.8$ or coronary narrowing $\geq 70 \%$. Patients were followed up for major adverse cardiovascular events. Prevalence is presented as patient numbers and percentage. Mann-Whitney $\mathrm{U}$ test was used to compare global MPRI between patients and normal volunteers.

Results: 13 patients had positive stress CMR with positive CCA (20.6\% of patient population), while 9 patients with positive stress CMR examinations had a negative CCA. 5 patients (7.9\%) had infarcts detected of which 2 patients had no stress perfusion defects. 12 patients had coronary artery stents inserted, whilst 1 patient declined stent placement. DM patients had lower global MPRI than normal volunteers $(n=7)(1.43 \pm 0.27$ vs $1.83 \pm 0.31$ respectively; $p<0.01)$. After a median follow-up of 653 days, there was no death, heart failure, acute coronary syndrome hospitalisation or stroke.

Conclusion: $20.6 \%$ of asymptomatic DM patients (with Framingham risk $\geq 20 \%$ ) had silent obstructive CAD. Furthermore, asymptomatic patients have reduced global MPRI than normal volunteers.

Trial Registration: ClinicalTrials.gov Registration Number: NCT03263728 on 28th August 2017; https://clinicaltrials.gov/ ct2/show/NCT03263728.

*Correspondence: myng2@hku.hk

${ }^{1}$ Department of Diagnostic Radiology, The University of Hong Kong,

Room 406, Block K, 102 Pokfulam Road, Hong Kong SAR, China

Full list of author information is available at the end of the article

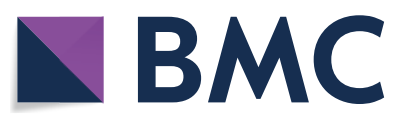

(c) The Author(s) 2020. This article is licensed under a Creative Commons Attribution 4.0 International License, which permits use, sharing, adaptation, distribution and reproduction in any medium or format, as long as you give appropriate credit to the original author(s) and the source, provide a link to the Creative Commons licence, and indicate if changes were made. The images or other third party material in this article are included in the article's Creative Commons licence, unless indicated otherwise in a credit line to the material. If material is not included in the article's Creative Commons licence and your intended use is not permitted by statutory regulation or exceeds the permitted use, you will need to obtain permission directly from the copyright holder. To view a copy of this licence, visit http://creativeco mmons.org/licenses/by/4.0/. The Creative Commons Public Domain Dedication waiver (http://creativecommons.org/publicdomain/ zero/1.0/) applies to the data made available in this article, unless otherwise stated in a credit line to the data. 
Keywords: Stress cardiac magnetic resonance, Type 2 diabetes, Asymptomatic, High cardiovascular risk, Screening

\section{Background}

Asymptomatic coronary artery disease (CAD) is highly prevalent (i.e. 17-59\%) in patients with diabetes mellitus type 2 (DM) [1]. In addition, cardiovascular disease remains the most common cause of death in DM patients [2]. Previous trials using coronary computed tomography angiograms or nuclear myocardial perfusion imaging to screen for asymptomatic obstructive CAD requiring intervention have been unsuccessful at reducing cardiovascular and all-cause mortality, when compared to optimised medical therapy where cardiovascular risk factors are treated to reduce cardiovascular complications [3, 4]. Possible reasons for this include, the choice of imaging modality, the intervention chosen (e.g. bare metal stents vs drug eluting stents), anatomical or fractional flow reserve (FFR) guidance and patient cohort (e.g. unselected DM patients vs high risk DM patients). Stress cardiac magnetic resonance (CMR) is ideally suited to assess this group of high risk patients, as there is no radiation exposure and it allows a more complete cardiac assessment including myocardial viability, left ventricular systolic and diastolic function. It has also shown to be non-inferior to FFR [5]. Nevertheless, a study using stress CMR to screen for myocardial ischaemia with catheter coronary angiography confirmation followed by intervention has never been performed. Thus the effectiveness of stress CMR to identify asymptomatic DM patients with silent ischaemia and its impact on patient outcomes are unknown.

Stress perfusion CMR identifies hemodynamically relevant coronary artery disease (CAD) on the basis of stress induced perfusion defects in the downstream supply territory. Furthermore, stress perfusion CMR enables the quantification of myocardial perfusion allowing for detection of underlying microvascular disease in the absence of obstructive CAD [6]. Previous studies quantifying myocardial perfusion have indicated that myocardial perfusion quantification is a useful prognostic marker of patient outcome [7]. Moreover, in DM patients, the presence of microvascular disease (MCAD) without obstructive CAD carries similar risk of adverse events as non-diabetic patients with obstructive CAD [7]. Global myocardial perfusion reserve index (MPRI) is a semi-quantifiable parameter which can be determined on stress perfusion CMR and has been shown to be diagnostic of MCAD [6]. Global MPRI provides information of the overall myocardial perfusion but does not differentiate epicardial CAD or MCAD. Stress-induced perfusion defects identified visually are usually suggestive of epicardial CAD whilst its absence is indicative of no significant epicardial CAD. However, when the search of stress induced perfusion defects visually is combined with global MPRI, additional diagnostic information can be provided by inferring the presence of MCAD when global MPRI is reduced and there is an absence of stress induced perfusion defects [6].

In order to determine the feasibility of a larger randomised controlled trial design for assessing the effectiveness of stress perfusion CMR, our study has two aims: (1) to determine the prevalence of myocardial ischaemia confirmed with catheter coronary angiography in asymptomatic high risk DM patients using stress CMR screening; (2) to quantify myocardial perfusion (i.e. MPRI) in asymptomatic high risk DM patients compared to healthy volunteers.

\section{Materials and methods}

The Cardiac Magnetic Resonance for Asymptomatic Patients with Type 2 Diabetes with Cardiovascular High Risk (CATCH) study (clinicalTrials.org: NCT03263728) was designed as a prospective cohort study. The study was approved by the local research ethics committee.

Patients were recruited consecutively from June 2017 to August 2018 at two diabetes clinics $(n=58)$ and one family medicine clinic $(n=5)$. All patients gave informed consent to be enrolled in the study.

Inclusion criteria were aged 60-80 years old, onset of DM at $\geq 30$ years old with no history of ketoacidosis, and Framingham Risk Score $\geq 20 \%$ (i.e. High risk based on Framingham Risk Score) [8]. Exclusion criteria were angina pectoris or chest discomfort, stress test or coronary angiography within 2 years, previous myocardial infarction, previous coronary artery stenting or bypass grafting, any clinical indication or contraindication for stress testing, any contraindication to stress CMR (e.g. previous anaphylaxis to adenosine), contraindication to gadolinium based contrast agent (e.g. Renal impairment with an estimated glomerular filtration rate $<30 \mathrm{ml} /$ $\mathrm{min} / 1.73 \mathrm{~m}^{2}$, life expectancy $<2$ years due to cancer or liver disease, contraindication to dual antiplatelet therapy, planned concomitant cardiac surgery, refusal or inability to provide informed consent and potential for non-compliance of the trial protocol.

63 patients (mean age 66 years, range $60-78$ years; $77.8 \%$ male) were enrolled into the study (see Fig. 1). 7 healthy volunteers aged $\geq 18$ years were recruited. Volunteers were deemed healthy if they had no cardiac symptoms or risk factors, no known cardiac disease, 


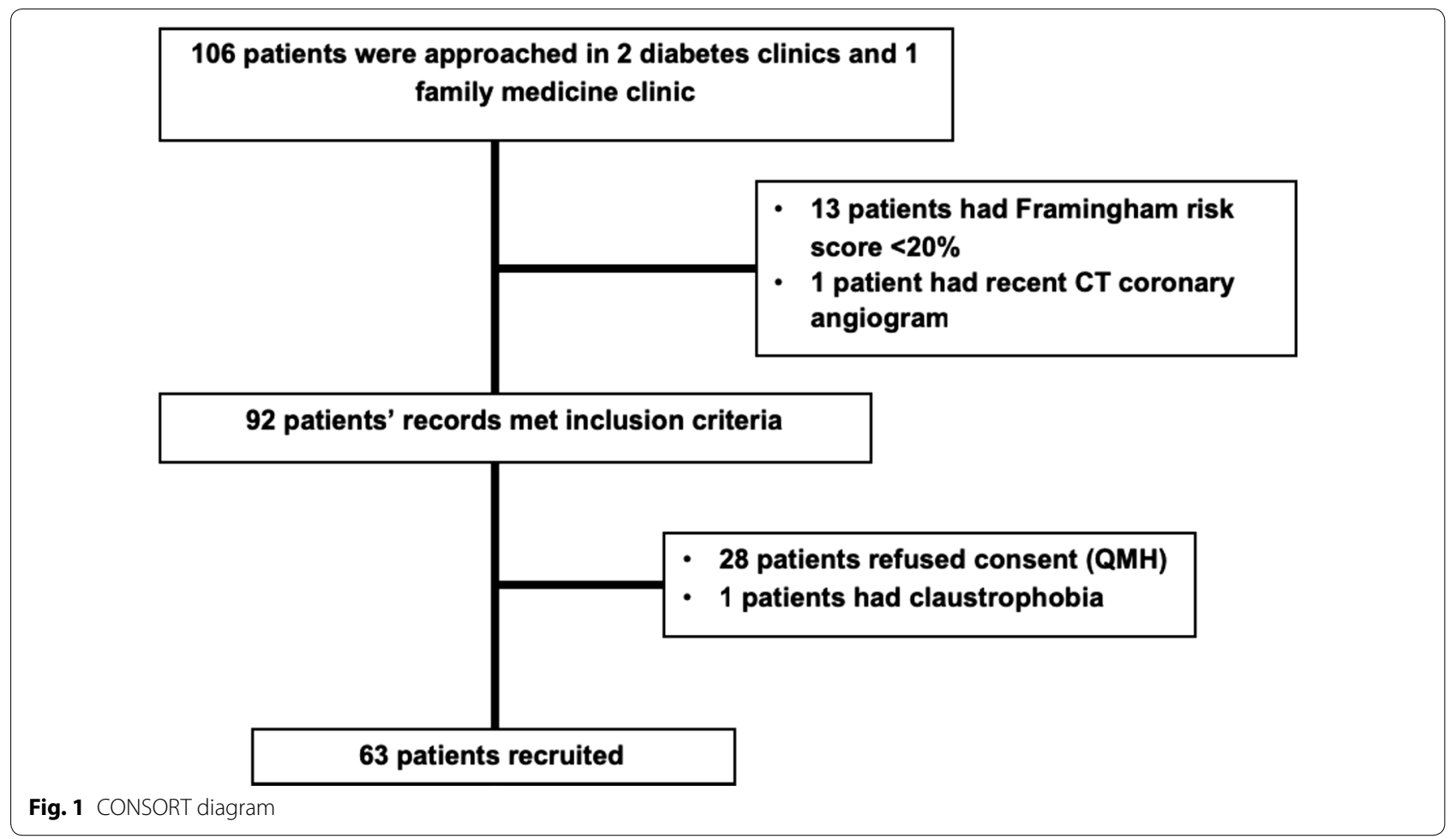

normal electrocardiogram, systolic and diastolic blood pressure $<140 \mathrm{mmHg}$ and $<100 \mathrm{mmHg}$ respectively, normal fasting glucose, normal brain-natriuretic peptide and normal stress CMR examination.

All study participants provided written informed consent.

\section{Workflow}

All recruited patients underwent stress CMR examinations (Fig. 2).

Patients with positive stress CMR examinations (see below for definition of positive/negative study) were referred to cardiology clinic to arrange catheter coronary angiography (CCA) with or without FFR (see

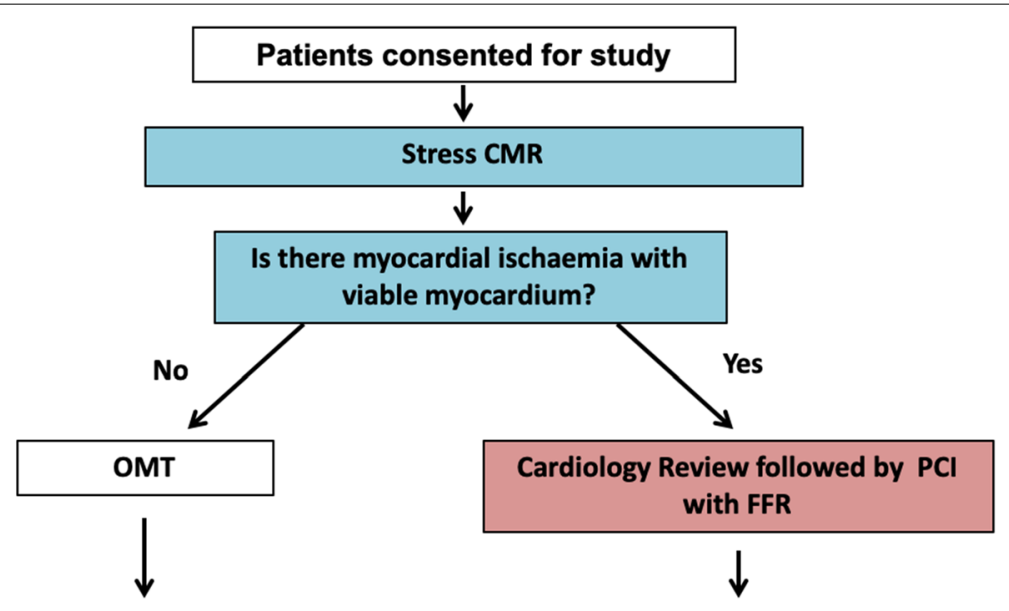

Follow-up assessment every 3 months (+/- cardiology or cardiothoracic surgery review)

Fig. 2 Study design. CMR cardiac magnetic resonance, OMT optimised medical therapy, FFR fractional flow reserve 


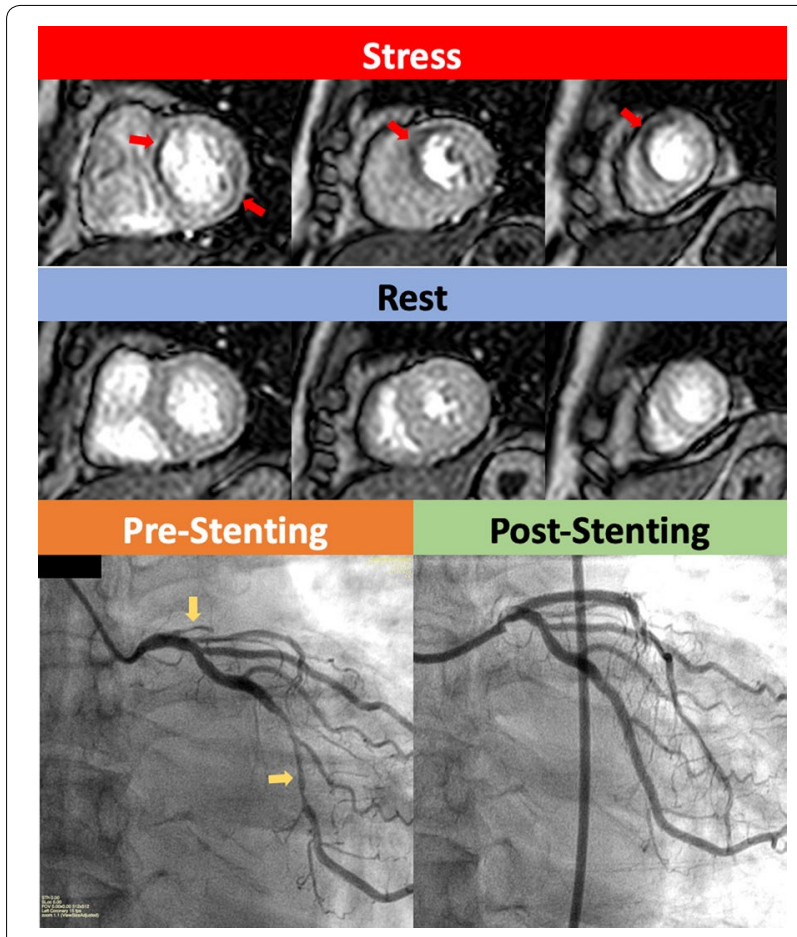

Fig. 3 Asymptomatic male patient with type 2 diabetes mellitus who was actively hiking. This patient was recruited into our study and had a positive screening stress cardiac magnetic resonance. Top row of images show stress perfusion defects (red arrows) in the basal, mid-ventricular and apical slices in the left anterior descending (LAD) territory as well as a stress perfusion defect in the left circumflex (LCX) territory on the basal slice in the inferolateral wall (red arrow). These perfusion defects resolved on the rest images. The catheter coronary angiogram showed chronic total occlusion of the LAD (yellow arrow) and obstructive CAD of the LCx (yellow arrow). Fractional flow reserve measurements of the $L C x$ was 0.69 . Post-stenting image in the bottom right shows the re-perfusion of the $L A D$ and expansion of the LCx narrowing

Fig. 3). At the time of catheterisation if deemed appropriate by the cardiologist, 2nd generation drug eluting coronary stents were inserted if the FFR is $\leq 0.8$ or coronary artery narrowing was $\geq 70 \%$.

Patients with a negative stress CMR examination would return to family practice or diabetes clinics to have optimised medical therapy and follow-up clinic appointments.

\section{CMR protocol}

All acquisitions were performed on a 3T Philips Achieva TX scanner, Philips Best, The Netherlands) and patients underwent multiplanar cine balanced steady state free precession imaging, stress/rest perfusion imaging and late gadolinium enhancement imaging.

\section{Stress and rest perfusion CMR technique}

Three short axis stress and rest perfusion images were acquired in the left ventricular (LV) basal, mid and apical aspects. For the stress and rest images, a T1 weighted fast gradient echo sequence was utilised [slice thickness $10 \mathrm{~mm}$, echo time (TE) $1.2 \mathrm{~ms}$, repetition time (TR) $2.5 \mathrm{~ms}$, flip angle $20^{\circ}$, field of view $320 \mathrm{~mm} \times 320 \mathrm{~mm}$ ].

Intravenous adenosine was administered $(0.14 \mathrm{mg} / \mathrm{kg} /$ $\mathrm{min}$ ) for up to $5 \mathrm{~min}$. If inadequate stress was achieved, infusion rate was increased by $50 \%$ as previously described [9]. First pass stress perfusion was acquired at peak stress with intravenous injection of $0.05 \mathrm{mmol} / \mathrm{kg}$ of gadoterate meglumine (injection rate: 3 to $4 \mathrm{ml} / \mathrm{s}$, with a subsequent $30 \mathrm{ml}$ saline flush at the same flow rate). After discontinuation of intravenous adenosine and a $10 \mathrm{~min}$ resting period allowing for sufficient contrast agent elimination, resting first pass perfusion imaging was performed with an additional injection of $0.05 \mathrm{mmol} / \mathrm{kg}$ of gadoterate meglumine.

An additional $0.1 \mathrm{mmol} / \mathrm{kg}$ was given prior to acquiring the late gadolinium enhancement (LGE) images after 8-15 min after the second gadoterate meglumine injection for rest perfusion images.

\section{Definition of positive and negative stress CMR examinations}

A positive study was defined as a study demonstrating a stress-induced perfusion defect. A stress-induced perfusion defect was defined as a dark sub-endocardial rim which lasts $>6$ heart beats on the stress images, larger than 1 pixel breadth and was not present on the rest images. A negative study is a study without a stress induced perfusion defect.

A positive stress CMR study was regarded as indicative of myocardial ischaemia that would likely benefit from coronary artery stenting. A negative stress CMR was considered a study which did not demonstrate evidence of myocardial ischaemia and thus would not benefit from coronary artery stenting.

\section{Data post-processing and interpretation}

CMR42 (Circle Inc., Calgary, Canada) was utilised to assess LV volumes, LV mass and LV ejection fraction. LV contouring of the endocardial and epicardial surfaces was performed on the short axis cine images in end-diastole and end-systole. Volumes and mass were corrected for body surface area. Body surface area was calculated using the Mosteller equation [10]. Calculation of the global MPRI was performed using semi-automated analysis (CMR42, Circle CVI, Calgary, Canada) by contouring the 
stress and rest perfusion images as previously described [6].

One blinded CMR analyst (WZ) performed the global MPRI measurements and the intraobserver measurements on 20 randomly selected subjects $>6$ months apart. A second CMR analyst (BC) performed the interobserver measurements.

Briefly, the blood pool and LV endocardial and epicardial borders were contoured on each stress and rest perfusion image to determine the stress/rest signal intensity up-slope ratios and normalised for the arterial input function. For patients without obstructive CAD and global MPRI was $<1.4$, this was classified as microvascular disease [6].

Images were assessed and reported for ischaemia, infarct and cardiac function by two fellowship trained cardiac radiologists through consensus (MYN, VV) with more than 10 years experience. If consensus could not be reached, an independent 3rd cardiac radiologist (BJW) would review the case.

\section{Catheter coronary angiography and FFR}

CCA and FFR was performed by two interventional cardiologists. FFR was undertaken if it could be done safely and there was luminal narrowing of $40-90 \%$. If FFR could not be performed, degree of coronary artery narrowing was determined by two interventional cardiologists at the time of procedure. At the time of catheterisation, $2^{\text {nd }}$ generation drug eluting coronary stents were inserted if FFR $\leq 0.8$ or coronary artery narrowing was $\geq 70 \%$.

\section{Fractional flow reserve procedure}

FFR was performed using a pressure wire at maximal hyperaemia. Hyperaemia was induced via infusion of $0.14 \mathrm{mg} / \mathrm{kg} / \mathrm{min}$ of adenosine intravenously. FFR was calculated as the mean distal coronary artery pressure divided by the mean aortic pressure during maximal hyperaemia.

\section{Patient follow-up}

Patients in both groups were followed up to ensure optimization of medical treatment and that CCA were performed in a timely manner. Major adverse cardiovascular events (MACE) were recorded (i.e. Death, heart failure, hospitalisation for acute coronary syndrome, stroke). This was done via out-patient clinics, review of the national patient electronic record system and telephone contact every three months. All patients were successfully followed up.

\section{Statistical analysis}

Primary outcome measures were (1) myocardial ischaemia detected by CMR and confirmed on CCA, (2) global MPRI of asymptomatic DM patients compared to normal volunteers. Myocardial ischaemia prevalence is presented as percentages. With the small number of volunteers, non-parametric tests were utilised (i.e. Mann-Whitney $\mathrm{U}$ tests and Fisher's exact test) to compare asymptomatic DM patients and healthy volunteers. Spearman's correlation was performed to correlate global MPRI with various continuous variables. To determine inter and intraobserver variability for global MPRI measurements, bias and limits of agreement were determined in 20 randomly selected cases. McNemar's Chi squared test was used to compare medication prescriptions before and 1 year after stress CMR examination. A p value $<0.05$ was considered statistically significant.

\section{Results}

63 patients were recruited. Our patient cohort were predominantly Chinese males (77.8\%) and high risk based on the Framingham Risk score (mean 36.4\%, SD 13.2\%). Our healthy volunteer cohort $(n=7)$ was slightly younger in age but not significantly different for gender. Detailed patient and volunteer characteristics are presented in Table 1.

LV and left atrial parameters are stated in Table 2. Compared to normal volunteers, patients had significantly higher LV mass index $(p=0.003)$ and smaller left atrial area index $(\mathrm{p}=0.04)$.

25 patients had positive stress CMR examinations. 5 patients (7.9\%) had infarcts detected of which only 2 of these patients with infarcts had no evidence of stress induced perfusion defects.

One patient's images had very poor image quality and could not be analysed for global MPRI. This patient was excluded from the analysis. Asymptomatic DM patients had lower global MPRI than normal volunteers $(1.43 \pm 0.27$ vs $1.83 \pm 0.31$ respectively; $\mathrm{p}<0.01)$. After excluding patients with obstructive CAD $(n=50)$, global MPRI remained significantly lower in patients $(1.45 \pm 0.27$ vs $1.83 \pm 0.31$ respectively; $\mathrm{p}<0.01)$. Amongst 49 patients, $51.0 \%(\mathrm{n}=25)$ had global MPRI $<1.4$ and thus could be classified as having microvascular disease.

Global MPRI correlated with age $(\mathrm{r}=-0.28, \mathrm{p}=0.021)$, BMI $(r=-0.31, p=0.009)$ and estimated glomerular filtration rate $(\mathrm{r}=0.26, \mathrm{p}=0.031)$. Other biochemical and CMR parameters did not show any significant correlation (see Table 3). For intraobserver variability, the bias was 0.015 and levels of agreement -0.12 to 0.15 . For interobserver variability, the bias was 0.061 and levels of agreement -0.16 to 0.29 .

22 of 25 patients with positive stress CMR (88\%) agreed to undergo CCA. 3 patients declined to proceed with CCA.

Of the 22 patients undergoing CCA, 31 vessels (47\%) had FFR performed. In total, 13 patients $(20.6 \%)$ had 
Table 1 Patient and normal volunteer cohort characteristics $(n=70)$

\begin{tabular}{|c|c|c|c|}
\hline Characteristic & $\begin{array}{l}\text { Asymptomatic patients with DM } \\
(n=63)\end{array}$ & Healthy volunteers $(n=7)$ & $\mathrm{p}$ \\
\hline Age (years) & $66.3 \pm 4.4$ & $60.4 \pm 4.1$ & $0.005^{*}$ \\
\hline Male & $77.8 \%$ & $42.8 \%$ & 0.07 \\
\hline Body mass index $\left(\mathrm{kg} / \mathrm{m}^{2}\right)$ & $25.8 \pm 3.9$ & $21.1 \pm 2.6$ & $0.003^{*}$ \\
\hline DM duration (years) & $15.8 \pm 8.8$ & - & - \\
\hline HbA1c (\%) & $7.2 \pm 1.0$ & - & - \\
\hline \multicolumn{4}{|l|}{ Cardiovascular risk factors } \\
\hline Systolic blood pressure (mmHg) & $138.1 \pm 9.0$ & $133.3 \pm 5.3$ & 0.14 \\
\hline Smoking & $11.1 \%$ & $0 \%$ & 0.46 \\
\hline High density lipoprotein (mmol/L) & $1.30 \pm 0.46$ & $1.53 \pm 0.43$ & 0.10 \\
\hline Total cholesterol (mmol/L) & $4.10 \pm 0.71$ & $5.26 \pm 0.40$ & $<0.001^{*}$ \\
\hline \multicolumn{4}{|l|}{ Diabetic complications } \\
\hline eGFR $\left(\mathrm{ml} / \mathrm{min} / 1.73 \mathrm{~m}^{2}\right)$ & $76.6 \pm 18.6$ & $87.9 \pm 10.6$ & 0.04 \\
\hline Microalbumin/creatnine ratio (mg/mmol) & $7.89 \pm 9.11$ & - & - \\
\hline Retinopathy & $14 \%$ & - & - \\
\hline Peripheral vascular disease & $1.4 \%$ & - & - \\
\hline \multicolumn{4}{|l|}{ Anti-hypertensives } \\
\hline Beta-blockers & $17.5 \%$ & $0 \%$ & 0.59 \\
\hline ACE inhibitor & $46.0 \%$ & $0 \%$ & 0.04 \\
\hline Calcium channel blockers & $65.1 \%$ & $0 \%$ & $<0.01^{*}$ \\
\hline Alpha-blockers & $7.9 \%$ & $0 \%$ & 1.00 \\
\hline Diuretics & $7.9 \%$ & $0 \%$ & 1.00 \\
\hline Angiotensin receptor blocker & $19.0 \%$ & $0 \%$ & 0.34 \\
\hline \multicolumn{4}{|l|}{ Lipid-modifying agents } \\
\hline Statin & $61.9 \%$ & $0 \%$ & $<0.01^{*}$ \\
\hline Fibrates & $1.6 \%$ & $0 \%$ & 1.00 \\
\hline \multicolumn{4}{|l|}{ Anti-hyperglycaemic agents } \\
\hline Acarbose & $1.6 \%$ & $0 \%$ & 1.00 \\
\hline Sulfonylureas & $36.5 \%$ & $0 \%$ & 0.09 \\
\hline SGLT2 inhibitor & $17.5 \%$ & $0 \%$ & 0.59 \\
\hline Metformin & $90.5 \%$ & $0 \%$ & $<0.01^{*}$ \\
\hline DDP-4 inhibitor & $41.3 \%$ & $0 \%$ & 0.04 \\
\hline Insulin & $30.2 \%$ & $0 \%$ & 0.18 \\
\hline Pioglitazone & $22.2 \%$ & $0 \%$ & 0.33 \\
\hline \multicolumn{4}{|l|}{ Anti-platelet agents } \\
\hline Clopidogrel & $6.3 \%$ & $0 \%$ & 1.00 \\
\hline Aspirin & $23.8 \%$ & $0 \%$ & 0.33 \\
\hline
\end{tabular}

DM diabetes mellitus type 2, HbA1C glycated haemoglobin, eGFR estimated glomerular filtration rate, ACE angiotension converting enzyme, SGLT-2 sodium-glucose co-transport 2 inhibitor, DDP-4 dipeptidyl peptidase-4

${ }^{*} \mathrm{p}<0.05$

positive stress CMR examinations with confirmed obstructive CAD on CCA. Of these 13 patients, 9 patients had FFR $\leq 0.8$ and a further 4 patients had coronary artery narrowing $\geq 70 \%$. 2 of the 9 patients with FFR $<0.8$ had complete occlusion of a coronary artery whilst 1 of the 4 patients with coronary artery narrowing $\geq 70 \%$ had complete occlusion of a coronary artery.
FFR could not be measured in these 3 occluded vessels. On a per vessel analysis, the number of correctly identified ischaemic territories (i.e. true positives) were 11 for left anterior descending artery, 3 for left circumflex artery and 4 for right coronary artery. See Table 4 for the per vessel analysis of all three coronary arteries.

In total, 12 patients had coronary artery stents inserted, with 1 patient declining coronary artery stent 
Table 2 Patient cohort's CMR parameters

\begin{tabular}{llll}
\hline CMR parameters & Asymptomatic DM patients $(\mathbf{n}=63)$ & Healthy volunteers $(\mathbf{n}=\mathbf{7})$ & $\mathbf{p}$ \\
\hline LVEDV indexed $\left(\mathrm{ml} / \mathrm{m}^{2}\right)$ & $75.4 \pm 14.8$ & $83.9 \pm 18.8$ & 0.19 \\
LVESV indexed $\left(\mathrm{ml} / \mathrm{m}^{2}\right)$ & $32.3 \pm 10.5$ & $43.3 \pm 26.8$ & 0.12 \\
Stroke volume $(\mathrm{ml})$ & $75.7 \pm 13.6$ & $76.0 \pm 25.9$ & 0.88 \\
LVEF $(\%)$ & $57.6 \pm 6.3$ & $56.6 \pm 6.6$ & 0.39 \\
LV mass indexed $\left(\mathrm{g} / \mathrm{m}^{2}\right)$ & $42.8 \pm 11.3$ & $28.5 \pm 8.2$ & $0.003^{*}$ \\
Cardiac output $(\mathrm{L} / \mathrm{min})$ & $5.50 \pm 1.10$ & $4.83 \pm 1.63$ & 0.26 \\
Left atrial area indexed $\left(\mathrm{cm}^{2} / \mathrm{m}^{2}\right)$ & $13.2 \pm 2.4$ & $15.0 \pm 1.9$ & $0.04^{*}$ \\
Right atrial area indexed $\left(\mathrm{cm}^{2} / \mathrm{m}^{2}\right)$ & $11.7 \pm 2.2$ & $13.3 \pm 2.5$ & 0.15 \\
LGE infarcts & $5(7.9 \%)$ & $0(0 \%)$ & 1.00 \\
Global MPRI & $1.42 \pm 0.28$ & $1.83 \pm 0.31$ & $0.003^{*}$ \\
\hline
\end{tabular}

Indexed parameters were corrected using body surface area

CMR cardiac magnetic resonance, DM diabetes mellitus type 2, LVEDV left ventricular end-diastolic volume, LVESV left ventricular end-systolic volume, LVEF left ventricular ejection fraction, $L V$ left ventricle, MPRI myocardial perfusion reserve index

${ }^{*} \mathrm{p}<0.05$

Table 3 Spearman's

correlation

coefficients between myocardial perfusion reserve index (MPRI) and clinical parameters, biochemical and cardiac magnetic resonance parameters in patients and normal volunteers $(n=70)$

\begin{tabular}{lcl}
\hline Characteristic & MPRI & \\
\cline { 2 - 3 } & Coefficient & $\mathbf{p}$ \\
\hline Age (years) & -0.28 & $0.021^{*}$ \\
BMI (m²) & -0.31 & $0.009^{*}$ \\
Diabetes duration (years) & 0.00 & 1.00 \\
HbA1c (\%) & 0.22 & 0.08 \\
Systolic blood pressure $(\mathrm{mmHg})$ & -0.19 & 0.12 \\
HDL (mmol/L) & 0.13 & 0.29 \\
Total cholesterol (mmol/L) & 0.17 & 0.15 \\
eGFR (ml/min/1.73 m²) & 0.26 & $0.031^{*}$ \\
Microalbumin/creatnine ratio $(\mathrm{mg} / \mathrm{mmol})$ & 0.01 & 0.96 \\
Framingham risk score $(\%)$ & -0.23 & 0.06 \\
CMR parameters & & \\
LVEDV indexed $\left(\mathrm{ml} / \mathrm{m}^{2}\right)$ & 0.18 & 0.15 \\
LVESV indexed $\left(\mathrm{ml} / \mathrm{m}^{2}\right)$ & 0.10 & 0.41 \\
LVEF $(\%)$ & 0.07 & 0.56 \\
LV mass indexed $\left(\mathrm{g} / \mathrm{m}^{2}\right)$ & -0.05 & 0.68 \\
Left atrial area indexed $\left(\mathrm{cm}{ }^{2}\right)$ & 0.05 & 0.70 \\
\hline
\end{tabular}

$B M$ body mass index, $H b A 1 C$ glycated haemoglobin, $H D L$ high density lipoprotein, eGFR estimated glomerular filtration rate, LVEDV left ventricular enddiastolic volume, LVEF left ventricular ejection fraction, $L V$ left ventricular ${ }^{*} \mathrm{p}<0.05$

placement. Of the 12 patients, 3 patients had 2 stents inserted whilst 9 patients had 1 stent inserted.

Patient follow-up 1 year post stress CMR demonstrated significant changes in medication prescribed to patients as compared to pre CMR status (see Table 5). In the whole cohort, there was an increase in betablocker $(p=0.014)$, statin $(p=0.0067)$, sodium-glucose
Table 4 Per vessel analysis of positive stress CMR results based on the 22 patients that underwent coronary catherization

\begin{tabular}{lcc}
\hline & $\begin{array}{l}\text { CMR LAD territory } \\
\text { +ve }\end{array}$ & $\begin{array}{l}\text { CMR LAD } \\
\text { territory } \\
\text { - ve }\end{array}$ \\
\hline LAD & 11 & 2 \\
Cath LAD territory +ve & 7 & 2 \\
Cath LAD territory -ve & & 1 \\
LCx & 3 & 12 \\
Cath LCx territory +ve & 6 & 1 \\
Cath LCx territory -ve & & 11 \\
RCA & 4 & \\
Cath RCA territory +ve & 6 & \\
Cath RCA Territory $-v e$ & & \\
\hline
\end{tabular}

co-transport 2 inhibitors (SGLT-2) $(\mathrm{p}=0.025)$, thiazolidinediones $(p=0.025)$, clopidogrel $(p=0.0047)$ and aspirin prescription $(\mathrm{p}=0.0013)$. When patients were divided into those with normal and abnormal stress CMR (see Table 6), calcium channel blockers $(\mathrm{p}=0.03)$, statins $((p=0.01)$, clopidogrel $(p=0.001)$ and aspirin $(p<0.001)$ prescription was significantly increased in patients with abnormal stress CMR. Over a median of 653 days (range 422-780 days), there was no death, heart failure, hospitalisation for acute coronary syndrome or stroke.

\section{Discussion}

To the best of our knowledge, this is the first study to investigate a stress perfusion CMR screening programme for high-risk asymptomatic DM patients. There were two main findings: (1) $20.6 \%$ of patients had a positive stress CMR examination with obstructive CAD and (2) 
Table 5 Cardiovascular and diabetic drug therapy from scan to 1 year post scan

\begin{tabular}{|c|c|c|c|}
\hline & Baseline & 1 year post scan & p \\
\hline \multicolumn{4}{|l|}{ Anti-hypertensives } \\
\hline Beta-blockers & $11(17 \%)$ & $17(27 \%)$ & $0.014^{*}$ \\
\hline ACE inhibitor & $29(46 \%)$ & $33(52 \%)$ & 0.10 \\
\hline Calcium channel blockers & $41(65 \%)$ & $44(69 \%)$ & 0.18 \\
\hline Alpha-blockers & $5(8 \%)$ & $7(11 \%)$ & 0.32 \\
\hline Diuretics & $5(8 \%)$ & $8(13 \%)$ & 0.08 \\
\hline ARB & $12(19 \%)$ & $13(21 \%)$ & 0.32 \\
\hline \multicolumn{4}{|l|}{ Lipid-modifying agents } \\
\hline Statin & $39(62 \%)$ & $48(76 \%)$ & $0.0067^{*}$ \\
\hline Fibrates & $1(2 \%)$ & $1(2 \%)$ & 1 \\
\hline \multicolumn{4}{|l|}{ Anti-hyperglycaemic agents } \\
\hline Acarbose & $1(2 \%)$ & $1(2 \%)$ & 1 \\
\hline Sulfonylureas & $23(37 \%)$ & $23(37 \%)$ & 1 \\
\hline SGLT-2 inhibitor & $11(17 \%)$ & $16(25 \%)$ & $0.025^{*}$ \\
\hline Metformin & $57(90 \%)$ & $59(94 \%)$ & 0.16 \\
\hline DDP-4 inhibitor & $26(41 \%)$ & $27(43 \%)$ & 0.71 \\
\hline Insulin & 19 (30\%) & $19(30 \%)$ & 1 \\
\hline Pioglitazone & $14(22 \%)$ & 19 (30\%) & $0.025^{*}$ \\
\hline \multicolumn{4}{|l|}{ Anti-platelet agents } \\
\hline Clopidogrel & $4(6 \%)$ & $12(19 \%)$ & $0.0047^{*}$ \\
\hline Aspirin & 15 (24\%) & 27 (43\%) & $0.0013^{*}$ \\
\hline
\end{tabular}

$A C E$ angiotension converting enzyme, $A R B$ angiotensin receptor blocker, SGLT-2 sodium-glucose co-transport 2 inhibitor, $D D P$-4 dipeptidyl peptidase-4

${ }^{*} \mathrm{p}<0.05$

asymptomatic DM patients had lower global MPRI compared to normal volunteers.

\section{Prevalence of silent obstructive CAD \& silent infarcts}

Our $20.6 \%$ prevalence of myocardial ischaemia in asymptomatic DM patients is in keeping with previously published results of $17-59 \%$ which utilised nuclear myocardial perfusion and exercise stress testing $[1,11,12]$. This data can now be used for more accurate sample size calculations if larger screening trials are planned. Furthermore, it should be noted that the published prevalence of silent ischaemia is based predominantly on imaging findings without catheter coronary angiography confirmation, thus we believe our stress CMR findings confirmed by angiography provide a more robust estimate of the prevalence of silent obstructive CAD in DM patients rather than just ischaemia detected on non-invasive imaging [12].

In our cohort, $7.9 \%$ of patients had silent myocardial infarcts which was consistent with previous studies (i.e. $1.9-17.5 \%$ of silent myocardial infarcts in asymptomatic DM patients) [13-16]. How these findings alters patient management and whether this alters patient outcome has not been directly studied. This study though provides
Table 6 Change in cardiovascular and diabetic drug therapy 1 year post scan based on having a normal or abnormal stress perfusion cardiac magnetic resonance (CMR) examination

\begin{tabular}{|c|c|c|c|}
\hline & \multicolumn{2}{|c|}{$\begin{array}{l}1 \text { year change } \\
\text { in medications }\end{array}$} & \multirow[b]{2}{*}{ p } \\
\hline & $\begin{array}{l}\text { Normal CMR } \\
(n=36)\end{array}$ & $\begin{array}{l}\text { Abnormal } \\
\text { CMR }(n=27)\end{array}$ & \\
\hline \multicolumn{4}{|l|}{ Anti-hypertensives } \\
\hline Beta-blockers & +2 & +4 & 0.39 \\
\hline ACE inhibitor & +1 & +3 & 0.80 \\
\hline Calcium channel blockers & -1 & +4 & $0.03^{*}$ \\
\hline Alpha-blockers & 0 & +2 & 0.76 \\
\hline Diuretics & 0 & +3 & 0.07 \\
\hline ARB & +1 & 0 & 1.00 \\
\hline \multicolumn{4}{|l|}{ Lipid-modifying agents } \\
\hline Statin & +1 & +8 & $0.01^{*}$ \\
\hline Fibrates & 0 & 0 & 1.00 \\
\hline \multicolumn{4}{|l|}{ Anti-hyperglycaemic agents } \\
\hline Acarbose & -1 & +1 & 0.68 \\
\hline Sulfonylureas & 0 & 0 & 1.00 \\
\hline SGLT-2 inhibitor & +2 & +3 & 0.64 \\
\hline Metformin & +1 & +1 & 1.00 \\
\hline DDP-4 inhibitor & +2 & -1 & 0.23 \\
\hline Insulin & 0 & +1 & 0.68 \\
\hline Pioglitazone & +3 & +2 & 1.00 \\
\hline \multicolumn{4}{|l|}{ Anti-platelet agents } \\
\hline Clopidogrel & 0 & +8 & $0.001^{*}$ \\
\hline Aspirin & 0 & +12 & $<0.001^{*}$ \\
\hline
\end{tabular}

Abnormal stress CMR was defined as having a stress perfusion defect and/or infarct

$A C E$ angiotension converting enzyme, $A R B$ angiotensin receptor blocker, SGLT-2 sodium-glucose co-transport 2 inhibitor, DDP-4 dipeptidyl peptidase-4

* $\mathrm{p}<0.05$

some insight by demonstrating increases in statin, clopidogrel and aspirin prescriptions as a result of an abnormal stress CMR examination. Furthermore, we found no major adverse cardiovascular events occurred in this cohort, but further study is warranted to assess the effect of stress CMR screening in terms of patient outcome.

\section{Coronary intervention based on stress perfusion CMR findings}

The insertion of coronary artery stents in asymptomatic patients with type 2 diabetes and obstructive CAD is not recommended in guidelines $[17,18]$. However, silent ischaemia in patients with type 2 diabetes is well established but the management of silent ischaemia in light of abnormal functional imaging findings is less certain. Indeed, the European Society of Cardiology has suggested that functional imaging could be utilised for silent 
ischaemia screening but the management of abnormal findings still requires further evidence [17]. At present both, European and American guidelines lack studies utilising stress perfusion CMR for ischaemia detection and prediction of inteventional outcomes in presence of stress perfusion CMR identified ischemia. Therefore this study provides the first patient outcomes as a result of screening with stress CMR and active intervention with coronary stenting. Furthermore, studies have frequently grouped stress perfusion CMR with other functional imaging studies [19] but various randomised controlled studies and meta-analyses have shown that stress perfusion CMR has superior diagnostic accuracy to many other functional studies as well as being non-inferior to FFR [5, 20-22]. Therefore, further research using stress perfusion CMR is warranted to determine if it may have a role in screening asymptomatic patients with type 2 diabetes.

\section{Global MPRI and MCAD—potential therapeutic target}

Using global MPRI, we demonstrated that asymptomatic DM patients had lower myocardial perfusion than normal volunteers. Moreover, $>50 \%$ of patients have evidence of MCAD. Previous studies have demonstrated reduced myocardial perfusion in patients with type 2 diabetes with chest pain [23], utilising only rest perfusion technique [24] and asymptomatic patients without investigating for obstructive coronary artery disease [25]. However, our study differs in that it establishes the proportion of patients with obstructive coronary artery disease, MCAD and those without microvascular disease for potential targeted therapy.

MCAD is a well established complication in type 1 and 2 diabetes mellitus [26]. MCAD carries significant independent prognostic significance as Murthy et al. previously demonstrated [7]. In their study, MCAD in DM patients was an independent predictor of MACE, and the risk was comparable to non-DM patients with obstructive CAD. MCAD has therefore increasingly become a focus of research interest to help reduce MACE in DM patients. However, there is currently no proven therapy to treat the condition.

Nonetheless, our sample size is small so further assessing global MPRI to identify microvascular dysfunction in diabetic patients and its prognostic significance needs to be undertaken. However, global MPRI or full quantification of myocardial blood flow on stress CMR [27] could represent a promising biomarker for targeting higher risk DM patients rather than identifying only obstructive CAD via the current clinical practice of identifying stress induced perfusion defects. This study adds to the growing literature of potential magnetic resonance imaging markers such as aortic stiffness [28], abdominal adiposity
[29] and high signal coronary artery plaque characterisation [30] in patients with type 2 diabetes that have shown promise in identifying patients with increased cardiovascular risk or adverse cardiac remodelling.

\section{Limitations}

Firstly, this was a small observational study to demonstrate the feasibility of utilising stress CMR in screening asymptomatic DM patients. Nonetheless, our study included outcome data which will allow sample size calculations to be performed for larger screening trials. Secondly, FFR was not performed in all coronary arteries. However, this likely represents real world situations where due to multiple factors FFR is not performed on all coronary arteries [31] such as narrowings $<50 \%$ or if the cardiologist deems there is a significant risk to patients if FFR is undertaken.

Thirdly, CCA was not performed in all patients so the true burden of obstructive CAD cannot be known. However, it would be hard to justify ethically to perform CCA on asymptomatic patients with type 2 diabetes with no evidence of ischaemia on stress CMR.

Lastly, our study did not set out to answer or refine the DM patients which would benefit most from screening. Using the Framingham risk score would lead to preferential recruitment of males as our study demonstrates. If MCAD or global MPRI is to be utilised as a marker for medical intervention, an alternative risk predictor may need to be utilised since women more commonly have MCAD and non-obstructive coronary arteries compared to males [32, 33]. Other screening trials have previously set $\geq 2$ risk factors as an inclusion criteria for DM patients $[34,35]$. This can prevent a recruitment bias towards males but further studies are required to determine the ideal cohort. Furthermore, there are a myriad of DM cardiovascular risk calculators but these best predict risk in cohorts with similar geographical location and ethnicity from which the studies originate [36-38]. This means that risk calculators may not be generalisable to other populations. Nonetheless, we chose the Framingham risk calculator as it is a widely accepted and validated risk calculator, even though its accuracy may be lower in certain ethnic groups.

\section{Conclusion}

This feasibility study on stress CMR screening of high risk asymptomatic DM patients demonstrated a $20.6 \%$ prevalence of myocardial ischaemia as confirmed by CCA with or without FFR and lower global MPRI in DM patients than normal volunteers. 


\section{Abbreviations}

CAD: Coronary artery disease; CCA: Catheter coronary angiography; CMR: Cardiovascular magnetic resonance; DM: Diabetes Mellitus type 2; FFR: Fractional flow reserve; LV: Left ventricle; MACE: Major adverse cardiovascular events; MCAD: Microvascular coronary artery disease; MPRI: Myocardial perfusion reserve index; SGLT-2: Sodium-glucose co-transport 2 inhibitors.

\section{Acknowledgements}

We are indebted to Ms Benedicte Coiffier for her help as the second CMR analyst.

\section{Authors' contributions}

MYN, WZ, CHL, EYTY, EYFW, KC, TPI, KHY were responsible for patient recruitment, data acquisition and/or analysis. MYN, W, CHL, EYTY, EYFW, KHY, BJW contributed to study design. MYN, WZ, EYFW, ATY, BJW contributed to statistical analysis and drafting of the manuscript. All authors read and approved the final manuscript.

\section{Funding}

This project is supported by the RSNA Research and Education Foundation. Grant number (RSD 1716).

\section{Availability of data and materials}

The datasets used and/or analysed during the current study are available from the corresponding author on reasonable request.

\section{Ethics approval and consent to participate}

Patient studies were conducted following human subject approval of the IRB of the Hong Kong West Cluster. All subjects gave informed written consent for study participation.

\section{Consent for publication}

The use of images has been permitted by patients with written consent forms.

\section{Competing interests}

The authors declare that they have no competing interests.

\begin{abstract}
Author details
1 Department of Diagnostic Radiology, The University of Hong Kong, Room 406, Block K, 102 Pokfulam Road, Hong Kong SAR, China. ${ }^{2}$ Department of Medical Imaging, The University of Hong Kong-Shenzhen Hospital, Shenzhen, China. ${ }^{3}$ Department of Medicine, The University of Hong Kong, Hong Kong, China. ${ }^{4}$ Department of Family Medicine and Primary Care, The University of Hong Kong, Hong Kong, China. ${ }^{5}$ Department of Cardiology, The University of Hong Kong-Shenzhen Hospital, Shenzhen, China. ${ }^{6}$ Departments of Medicine and Medical Imaging, St. Michael's Hospital, Toronto, Canada. ${ }^{7}$ University of Toronto, Toronto, Canada. ${ }^{8}$ Department of Medicine, Tung Wah Hospital, Hong Kong, China. ${ }^{9}$ Department of Medical Imaging, University of Toronto, Toronto, Canada. ${ }^{10}$ Department of Medical Imaging, University Health Network, Toronto, Canada.
\end{abstract}

Received: 22 January 2020 Accepted: 19 March 2020

Published online: 31 March 2020

\section{References}

1. Upchurch CT, Barrett EJ. Clinical review: screening for coronary artery disease in type 2 diabetes. J Clin Endocrinol Metab. 2012;97:1434-42.

2. Mozaffarian D, Benjamin EJ, Go AS, Arnett DK, Blaha MJ, et al. Heart disease and stroke statistics-2016 update: a report from the American Heart Association. Circulation. 2015;133:e38-360.

3. Muhlestein JB, Lappé DL, Lima JC, et al. Effect of screening for coronary artery disease using CT angiography on mortality and cardiac events in high-risk patients with diabetes: the FACTOR-64 randomized clinical trial. JAMA. 2014;312:2234-43.

4. Young LH, Wackers FJ, Chyun DA, Davey JA, Barrett EJ, Taillefer R, Heller GV, Iskandrian AE, Wittlin SD, Filipchuk N, Ratner RE, Inzucchi SE, Investigators D. Cardiac outcomes after screening for asymptomatic coronary artery disease in patients with type 2 diabetes: the DIAD study: a randomized controlled trial. JAMA. 2009;301:1547-55.
5. Nagel E, Greenwood JP, McCann GP, Bettencourt N, Shah AM, Hussain ST, Perera D, Plein S, Bucciarelli-Ducci C, Paul M, Westwood MA, Marber M, Richter WS, Puntmann VO, Schwenke C, Schulz-Menger J, Das R, Wong J, Hausenloy DJ, Steen H, Berry C, Investigators M-I. Magnetic resonance perfusion or fractional flow reserve in coronary disease. N Engl J Med. 2019;380:2418-28.

6. Liu A, Wijesurendra RS, Liu JM, Forfar JC, Channon KM, Jerosch-Herold M, Piechnik SK, Neubauer S, Kharbanda RK, Ferreira VM. Diagnosis of microvascular angina using cardiac magnetic resonance. J Am Coll Cardiol. 2018;71:969-79.

7. Murthy VL, Naya M, Foster CR, Gaber M, Hainer J, Klein J, Dorbala S, Blankstein R, Di Carli MF. Association between coronary vascular dysfunction and cardiac mortality in patients with and without diabetes mellitus. Circulation. 2012;126:1858-68.

8. D'Agostino RB Sr, Vasan RS, Pencina MJ, Wolf PA, Cobain M, Massaro JM, Kannel WB. General cardiovascular risk profile for use in primary care: the Framingham Heart Study. Circulation. 2008;117:743-53.

9. Karamitsos TD, Ntusi NA, Francis JM, Holloway CJ, Myerson SG, Neubauer S. Feasibility and safety of high-dose adenosine perfusion cardiovascular magnetic resonance. J Cardiovasc Magn Reson. 2010;12:66.

10. Mosteller RD. Simplified calculation of body-surface area. N Engl J Med. 1987:317:1098

11. Naka M, Hiramatsu K, Aizawa T, Momose A, Yoshizawa K, Shigematsu S, Ishihara F, Niwa A, Yamada T. Silent-myocardial-ischemia in patients with non-insulin-dependent diabetes-mellitus as judged by treadmill exercise testing and coronary angiography. Am Heart J. 1992;123:46-53.

12. Miller TD, Rajagopalan N, Hodge DO, Frye RL, Gibbons RJ. Yield of stress single-photon emission computed tomography in asymptomatic patients with diabetes. Am Heart J. 2004;147:890-6.

13. Davis TME, Fortun P, Mulder J, Davis WA, Bruce DG. Silent myocardial infarction and its prognosis in a community-based cohort of type 2 diabetic patients: the Fremantle Diabetes Study. Diabetologia. 2004:47:395-9.

14. Scheidt-Nave C, Barrett-Connor E, Wingard DL. Resting electrocardiographic abnormalities suggestive of asymptomatic ischemic heart disease associated with non-insulin-dependent diabetes mellitus in a defined population. Circulation. 1990;81:899-906.

15. MacDonald MR, Petrie MC, Home PD, Komajda M, Jones NP, Beck-Nielsen $\mathrm{H}$, Gomis R, Hanefeld M, Pocock SJ, Curtis PS, McMurray JJ. Incidence and prevalence of unrecognized myocardial infarction in people with diabetes: a substudy of the Rosiglitazone Evaluated for Cardiac Outcomes and Regulation of Glycemia in Diabetes (RECORD) study. Diabetes Care. 2011;34:1394-6.

16. Davis TM, Coleman RL, Holman RR and Group U. Prognostic significance of silent myocardial infarction in newly diagnosed type 2 diabetes mellitus: United Kingdom Prospective Diabetes Study (UKPDS) 79. Circulation. 2013;127:980-7.

17. Cosentino F, Grant PJ, Aboyans V, Bailey CJ, Ceriello A, Delgado V, Federici M, Filippatos G, Grobbee DE, Hansen TB, Huikuri HV, Johansson I, Juni P, Lettino M, Marx N, Mellbin LG, Ostgren CJ, Rocca B, Roffi M, Sattar N, Seferovic PM, Sousa-Uva M, Valensi P, Wheeler DC, ESC Scientific Document Group. 2019 ESC guidelines on diabetes, pre-diabetes, and cardiovascular diseases developed in collaboration with the EASD. Eur Heart J. 2020;41(2):255-323.

18. Fox CS, Golden SH, Anderson C, Bray GA, Burke LE, de Boer IH, Deedwania P, Eckel RH, Ershow AG, Fradkin J, Inzucchi SE, Kosiborod M, Nelson RG, Patel MJ, Pignone M, Quinn L, Schauer PR, Selvin E, Vafiadis DK, American Heart Association Diabetes Committee of the Council on L, Cardiometabolic Health CoCCCoC, Stroke Nursing CoCS, Anesthesia CoQoC, Outcomes R and the American Diabetes A. Update on prevention of cardiovascular disease in adults with type 2 diabetes mellitus in light of recent evidence: a scientific statement from the American Heart Association and the American Diabetes Association. Circulation. 2015;132:691-718.

19. Maron DJ, Hochman JS, O'Brien SM, Reynolds HR, Boden WE, Stone GW, Bangalore S, Spertus JA, Mark DB, Alexander KP, Shaw L, Berger JS, Ferguson TB, Williams DO, Harrington RA, Rosenberg Y. International study of comparative health effectiveness with medical and invasive approaches (ISCHEMIA) trial: rationale and design. Am Heart J. 2018;201:124-35.

20. Greenwood JP, Maredia N, Younger JF, Brown JM, Nixon J, Everett CC, Bijsterveld P, Ridgway JP, Radjenovic A, Dickinson CJ, Ball SG, Plein S. Cardiovascular magnetic resonance and single-photon emission computed 
tomography for diagnosis of coronary heart disease (CE-MARC): a prospective trial. Lancet. 2012;379:453-60.

21. Takx RA, Blomberg BA, El Aidi H, Habets J, de Jong PA, Nagel E, Hoffmann $U$, Leiner T. Diagnostic accuracy of stress myocardial perfusion imaging compared to invasive coronary angiography with fractional flow reserve meta-analysis. Circu Cardiovasc Imaging. 2015;8:e002666.

22. Danad I, Szymonifka J, Twisk JW, Norgaard BL, Zarins CK, Knaapen P, Min JK. Diagnostic performance of cardiac imaging methods to diagnose ischaemia-causing coronary artery disease when directly compared with fractional flow reserve as a reference standard: a meta-analysis. Eur Heart J. 2016;38:991-8.

23. Larghat AM, Swoboda PP, Biglands JD, Kearney MT, Greenwood JP, Plein S. The microvascular effects of insulin resistance and diabetes on cardiac structure, function, and perfusion: a cardiovascular magnetic resonance study. Eur Heart J Cardiovasc Imaging. 2014;15:1368-76.

24. Liu X, Yang Z-G, Gao Y, Xie L-J, Jiang L, Hu B-Y, Diao K-Y, Shi K, Xu H-Y, Shen $M-T$, Ren $Y$, Guo Y-K. Left ventricular subclinical myocardial dysfunction in uncomplicated type 2 diabetes mellitus is associated with impaired myocardial perfusion: a contrast-enhanced cardiovascular magnetic resonance study. Cardiovasc Diabetol. 2018;17:139.

25. Sørensen MH, Bojer AS, Broadbent DA, Plein S, Madsen PL, Gæde P. Cardiac perfusion, structure, and function in type 2 diabetes mellitus with and without diabetic complications. Eur Heart J Cardiovasc Imaging. 2019. https://doi.org/10.1093/ehjci/jez266.

26. Di Carli MF, Janisse J, Grunberger G, Ager J. Role of chronic hyperglycemia in the pathogenesis of coronary microvascular dysfunction in diabetes. J Am Coll Cardiol. 2003;41:1387-93.

27. Hsu LY, Jacobs M, Benovoy M, Ta AD, Conn HM, Winkler S, Greve AM, Chen MY, Shanbhag SM, Bandettini WP, Arai AE. Diagnostic performance of fully automated pixel-wise quantitative myocardial perfusion imaging by cardiovascular magnetic resonance. JACC Cardiovasc Imaging. 2018;11:697-707

28. Swoboda PP, Erhayiem B, Kan R, McDiarmid AK, Garg P, Musa TA, Dobson LE, Witte KK, Kearney MT, Barth JH, Ajjan R, Greenwood JP, Plein S. Cardiovascular magnetic resonance measures of aortic stiffness in asymptomatic patients with type 2 diabetes: association with glycaemic control and clinical outcomes. Cardiovasc Diabetol. 2018;17:35.

29. Schlett CL, Lorbeer R, Arndt C, Auweter S, Machann J, Hetterich H, Linkohr B, Rathmann W, Peters A, Bamberg F. Association between abdominal adiposity and subclinical measures of left-ventricular remodeling in diabetics, prediabetics and normal controls without history of cardiovascular disease as measured by magnetic resonance imaging: results from the KORA-FF4 study. Cardiovasc Diabetol. 2018;17:88.

30. Hosoda H, Asaumi Y, Noguchi T, Morita Y, Kataoka Y, Otsuka F, Nakao K, Fujino M, Nagai T, Nakai M, Nishimura K, Kono A, Komori Y, Hoshi T, Sato A, Kawasaki T, Izumi C, Kusano K, Fukuda T, Yasuda S. Three-dimensional assessment of coronary high-intensity plaques with T1-weighted cardiovascular magnetic resonance imaging to predict periprocedural myocardial injury after elective percutaneous coronary intervention. J Cardiovasc Magn Reson. 2020;22:5.

31. Achenbach S, Rudolph T, Rieber J, Eggebrecht H, Richardt G, Schmitz T, Werner N, Boenner F, Mollmann H. Performing and interpreting fractional flow reserve measurements in clinical practice: an expert consensus document. Interv Cardiol. 2017:12:97-109.

32. Johnson BD, Shaw LJ, Buchthal SD, Merz CNB, Kim HW, Scott KN, Doyle M, Olson MB, Pepine CJ, den Hollander J, Sharaf B, Rogers WJ, Mankad S, Forder JR, Kelsey SF, Pohost GM, National Institutes of Health-National Heart L, Blood I. Prognosis in women with myocardial ischemia in the absence of obstructive coronary disease: results from the National Institutes of Health-National Heart, Lung, and Blood Institute-Sponsored Women's Ischemia Syndrome Evaluation (WISE). Circulation. 2004;109:2993-9.

33. Reis SE, Holubkov R, Smith AJC, Kelsey SF, Sharaf BL, Reichek N, Rogers WJ, Merz CNB, Sopko G, Pepine CJ, Investigators W. Coronary microvascular dysfunction is highly prevalent in women with chest pain in the absence of coronary artery disease: results from the NHLBI WISE study. Am Heart J. 2001;141:735-41.

34. Faglia E, Manuela M, Antonella Q, Michela G, Vincenzo C, Maurizio C, Roberto M, Alberto M. Risk reduction of cardiac events by screening of unknown asymptomatic coronary artery disease in subjects with type 2 diabetes mellitus at high cardiovascular risk: an open-label randomized pilot study. Am Heart J. 2005;149:e1-6.

35. Lièvre MM, Moulin P, Thivolet C, Rodier M, Rigalleau V, Penfornis A, Pradignac A, Ovize M. Detection of silent myocardial ischemia in asymptomatic patients with diabetes: results of a randomized trial and meta-analysis assessing the effectiveness of systematic screening. Trials. 2011;12:23.

36. Kengne AP, Patel A, Colagiuri S, Heller S, Hamet P, Marre M, Pan CY, Zoungas S, Grobbee DE, Neal B, Chalmers J, Woodward M and Group AC. The Framingham and UK Prospective Diabetes Study (UKPDS) risk equations do not reliably estimate the probability of cardiovascular events in a large ethnically diverse sample of patients with diabetes: the Action in Diabetes and Vascular Disease: Preterax and Diamicron-MR Controlled Evaluation (ADVANCE) Study. Diabetologia. 2010;53:821-31.

37. Hense HW, Schulte H, Lowel H, Assmann G, Keil U. Framingham risk function overestimates risk of coronary heart disease in men and women from Germany-results from the MONICA Augsburg and the PROCAM cohorts. Eur Heart J. 2003;24:937-45.

38. Bertoluci MC, Rocha VZ. Cardiovascular risk assessment in patients with diabetes. Diabetol Metab Syndr. 2017:9:25.

\section{Publisher's Note}

Springer Nature remains neutral with regard to jurisdictional claims in published maps and institutional affiliations.
Ready to submit your research? Choose BMC and benefit from:

- fast, convenient online submission

- thorough peer review by experienced researchers in your field

- rapid publication on acceptance

- support for research data, including large and complex data types

- gold Open Access which fosters wider collaboration and increased citations

- maximum visibility for your research: over $100 \mathrm{M}$ website views per year

At BMC, research is always in progress.

Learn more biomedcentral.com/submissions 